\title{
Seismicity Pattern in Southern Africa from 1986 to 2009
}

\author{
Aderemi A. Alabi ${ }^{1}$, Olukayode D. Akinyemi ${ }^{1}$ \& Adebambo Adewale ${ }^{2}$ \\ ${ }^{1}$ Department of Physics, Federal University of Agriculture, Abeokuta, Nigeria \\ ${ }^{2}$ Department of SLT, Moshood Abiola Polytechnic, Abeokuta, Nigeria \\ Correspondence: Aderemi A. Alabi, Department of Physics, College of Natural Sciences, Federal University of \\ Agriculture, PMB 2240 Abeokuta, Nigeria. E-mail: derylab@yahoo.com
}

Received: July 24, 2012

doi:10.5539/esr.v2n2p1
Accepted: December 12, 2012 Online Published: December 31, 2012

URL: http://dx.doi.org/10.5539/esr.v2n2p1

\begin{abstract}
Study of Seismicity pattern in the Southern Africa from 1986 to 2009 was undertaken natural earthquakes with body wave magnitude, $\mathrm{Mb} \geq 3.0$. The earthquake seismology, quantification, statistics of the region was studied. Statistical analyses such as measured central tendencies and spread, pictorial representations (histogram) and time series (moving average) were employed. The Gutenberg-Richter analyses was carried out and this gave $a=5.75$ and $b=1.23$ for the two constants. The result shows that the Southern Africa region which is located in an intraplate earthquake belt is generally characterized by small and minor earthquakes with low spatial spread. The seismic events were found to be irregular. The probability of occurrence of major earthquakes in this region in the nearest future was discovered to be low. However, a large earthquake could take place due to uncertainties associated with earthquake predictions, especially in intraplate regions.
\end{abstract}

Keywords: Gutenberg- Richter recurrence law, seismicity, epicenter, intraplate region, tectonic stress

\section{Introduction}

The Southern Africa region is located in an intraplate area and it is associated with a rather complex seismic characteristics. Most devastating earthquakes are tectonics origin and the epicenter of over $90 \%$ of global natural earthquakes take place at boundary of major plates. The seismicity of Southern Africa with its sporadic, scattered, shallow earthquakes belong to the type intraplates activity which may occasionally reach critical value such as event of December 8th 1976 in Welkom, Orange Free State scale that reach the magnitude of 5.5 and others with slightly higher values (Uzoegbo \& Li, 2002). The mining activities have contributed immensely to the hosting of seismic events, it has been established that up to 40 or more tremors are recorded monthly. The recordings are mainly in the places surrounding the gold mining areas like the Transvaal and Orange Free State. Many are also recorded around the Carleton and Klerksdorp areas annually. Deep-level mining as is found in South Africa involves working in the earth's crust where there is naturally occurring seismicity (which is very simply the release of energy in the rock mass). This occurs as, globally, the continental plates shift and in reaction to changes in the force fields (localized energy) in the earth's crust. The largest mining-related ever to occur in South Africa registered 5.3 on the local Richter magnitude scale (ML) on 9 March 2005. An unusually large earthquake of $\mathrm{ML}=7.3$ occurred in Mozambique on 23 February 2006, at the southernmost end of the East African Rift System (Linzer et al., 2007).

Earthquakes predication is one of the ultimate goal of seismology, study of past and present events for precursory patterns is very useful to minimize effect of earthquakes destructions on both materials and living beings. Scientists have been trying to understand earthquake process for centuries (Darwin, 1845).

The main objective of this study is to come up into some vital information about the pattern and frequency of occurrence of earthquakes in the study area.

This location is between Latitude $35^{\circ} \mathrm{S}$ and $15^{\circ} \mathrm{S}$ and Longitude $10^{\circ} \mathrm{E}$ and $50^{\circ} \mathrm{E}$ in the Southern Africa region, a portion of the Africa plate. This is achieved by analyzing the history of seismic activity in the recent past and their distribution in the area. The study also considered the trend of increase in term of general number of events taking place in the area. This was with regard to magnitude, the time rate of increase and focal depths encountered on several occasions; the study was also taking into account the nature of the spread in case such exists. In this case extensions of seismically active portions are investigated to make the deductions on the probability of earthquake occurrence there. 


\section{Seismicity of Study Area}

The study of seismicity of Southern Africa started as far back as 1910 (Uzoegbo \& Warnitchai, 2000). Recently, Scientist and Researchers have put in great effort in the earthquake hazard mapping of the region [South Africa, Mozambique, Zimbabwe, Botswana, Namibia, Lesotho, Swaziland, Southern Angola and Zambia].

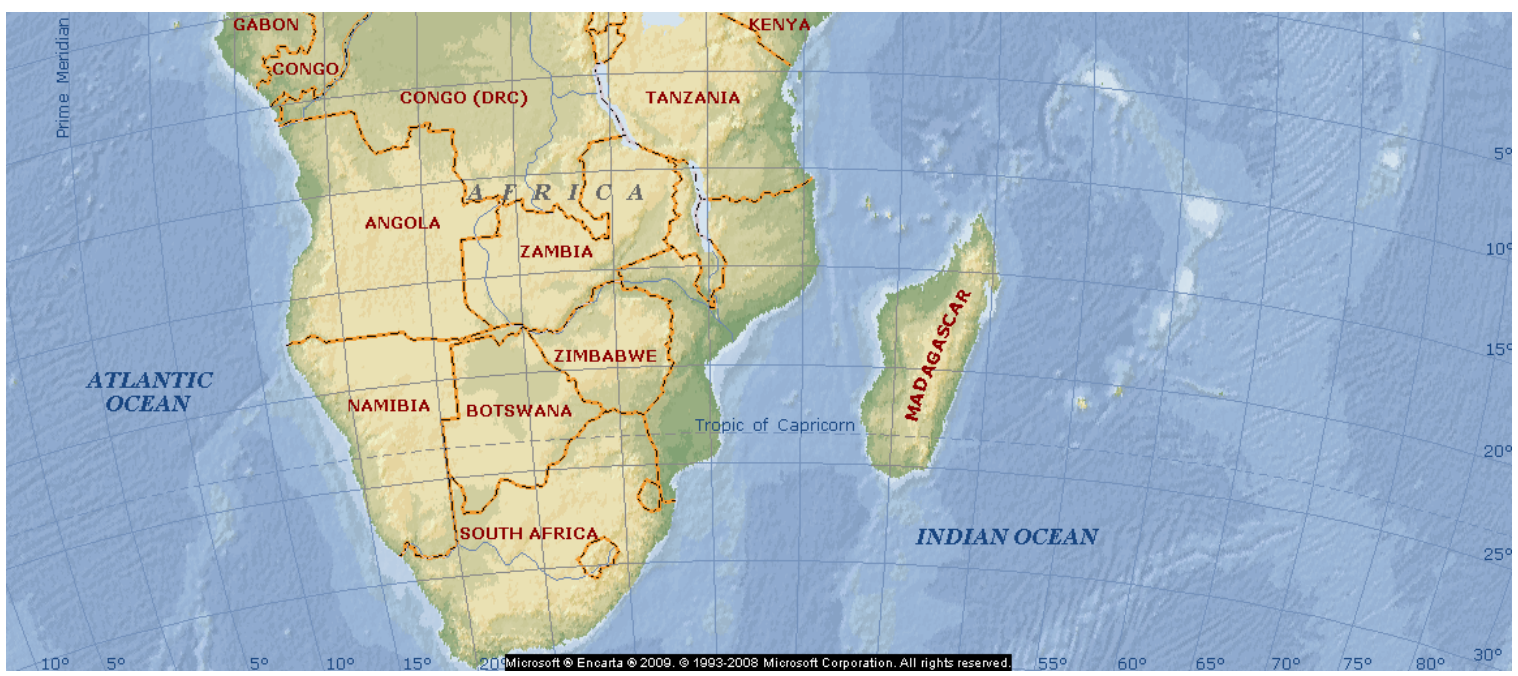

Figure 1. Map of Southern Africa- the study region

The study area, Southern Africa region, a portion of the African plate, is located between Latitude $35^{\circ} \mathrm{S}$ and $15^{\circ} \mathrm{S}$ and Longitude $10^{\circ} \mathrm{E}$ and $50^{\circ} \mathrm{E}$. The map of the major tectonic plate indicates that the Southern Africa region is not traversed by any major tectonic plate boundary. Southern Africa is located in the interior of large Africa plate. The borders of this plate to the south are located in the mid-Atlantic and mid-India Ocean ridges.

The continent does not appear to be affected by the distance tremors of this belt. The East Africa rift system is a clear line intraplate seismicity, which has been shown to extend to Southern Africa.

In Southern Africa, the areas of activity seismicity are in Mozambique, Zimbabwe and Northern Botswana. These activities are believed to be an extension of the East Africa rift system. The investigation of the catalogue of earthquake shows that South Africa has experienced few major earthquake events. Among these are the earthquake of Orange Free State in 1912 ref. (magnitude ix on Rossi scale) and Ceres earthquakes in the Cape Province 1969, with a 6.3 magnitude on the Richter scale. The seismicity areas are located in the interior of the major tectonics plate in low but it is difficult to correlate with known tectonics characteristics.

The south-western Cape has one of the highest levels of seismicity in South Africa, which is characterized by its dual source of seismicity comprising mine related events and tectonic origin earthquakes.

Historically, the most severe earthquake of magnitude 6.3 occurred on 29 September 1969 in Ceres, $100 \mathrm{~km}$ northeast of Cape Town. The event resulted in loss of lives and numerous buildings damaged in the town of Tulbagh. On 4 September 1809, a seismic event estimated at magnitude 6.3, occurred at the Milnerton Fault, a mere $10 \mathrm{~km}$ from Cape Town CBD and the location of the Cape Town Stadium.

The largest mine related event in the history of South Africa occurred on 5 March 2005 in the Klerksdorp (Stilfontein) gold mining district, $200 \mathrm{~km}$ west of Johannesburg, which reached a magnitude of 5.3. Below ground, substantial damage was observed within the mines, while above ground, the structural damage to property was relatively low.

Majority of seismic events in region of magnitude below 5.0 originate in Mining areas. The epicenters of mine tremors are shallow, unusually lower than $2 \mathrm{~km}$ and are hazardous only immediate neighbor to the mines. The natural earthquakes have a much lower frequency of occurrence but may be more hazardous to the region. Scientist concludes that irregular pattern of epicenter does not correlate with geological and physiographic features. However, it is observed that, no part of the region is free from occasionally shocks. 


\section{Materials and Methods}

The data used for this study was obtained from website of the Northern California Earthquakes Data Centre. The Centre is a joint project of the University of California Berkley Seismological laboratory and United States Geological Survey (USGS). It is also available in global earthquake catalogue produced from contributions of Advanced Natural Seismic Source (ANSS). The region of study is located between latitude $35^{\circ} \mathrm{S}$ and $15^{\circ} \mathrm{S}$ and longitude $10^{\circ} \mathrm{E}$ and $50^{\circ} \mathrm{E}$.

The data covers a 24-year period from January 1st 1986 to December 31st 2009 and in all there were 4219 events. The minimum magnitude selected in the catalog search is 3.0 and the maximum magnitude is 8.0. The minimum focal depth selected is $0.0 \mathrm{~km}$ while the maximum is $700 \mathrm{~km}$, the event type is $\mathrm{E}$, this indicates that all are deep events. Each datum comprised data of occurrence of earthquake, origin time, coordinates of epicenter, magnitude, event identification and focal depth of earthquake. To study the seismic pattern or hazard of a region, there is a need to detect all probable seismic sources and check their potential to produce strong ground motion (Amiri et al., 2008). Earthquake frequency-magnitude relation helps to understand seismic activity in an area (Ghosh, 2007). The relationship between the size distributions of earthquakes over a large range of magnitudes in a seismogenic volume can be described by a power law equation (Abercrombie, 1995).

The relationship between size distribution of earthquakes and magnitude was first discovered in 1939 in Japan and later by Gutenberg and Richter (1944) in California.

One of the forms of power law is given as;

$$
\log N=a+b M
$$

Where $\mathrm{N}$ is the cumulative number of earthquakes with magnitude is greater than or equal to $\mathrm{M}$ and $\mathrm{a}$ and $\mathrm{b}$ are constants.

The parameter ' $a$ ' describes the productivity of a volume and $b$, the slope of the frequency-Magnitude distribution, describes the relative size distribution of events.

The Gutenberg-Richter (G-R), frequency-magnitude linear relation equation (Equation 1)

$$
\log (N * 100)=a^{*}-b M
$$

Where $\mathrm{a}^{*}=\mathrm{a}+2$.

' $a$ ' is a function of quantity of earthquakes throughout the years covered in the study area while b, in general is approximately equal to 1 . Large value for $b(>1)$ indicates predominantly small earthquakes while small values of $\mathbf{b}(<1)$ implies predominantly large earthquakes. The value of ' $\mathbf{a}$ ' and $\mathbf{b}$ are obtained from intercept and slope of the graph of Log N against M. The b-value in Gutenberg-Richter law Equation (1) is very important because it reveals a lot in the studies of seismotectonic, seismic risk analysis, prediction and hazard. Therefore, its correct computation represents an important challenge and gives vital information as per seismology of a given area.

The following features of the events were considered; frequency distribution, cumulative frequency distribution of magnitude. The pattern and frequency of occurrence of earthquakes in the study area was investigated and the trend of increase in term of general number of events taken place in the area was also considered. This was with regard to magnitude, the time rate of increases and focal depth encountered on several occasions.

\subsection{Frequency-Magnitude Distribution of Events}

The distribution of magnitudes with the number of events, cumulative frequency, fc, percentage, $\mathrm{Nc}=\mathrm{fc} / 24$ and $\log (100 * \mathrm{Nc})$ in the study area were shown in Tables 1 and 2 .

Table 1. Distribution of events according to magnitude of earthquakes for each year

\begin{tabular}{lllllll}
\hline Year/Mag & $3.0-3.9$ & $4.0-4.9$ & $5.0-5.9$ & $6.0-6.9$ & $7.0-7.9$ & Total \\
\hline 1986 & 12 & 33 & 3 & 0 & 0 & 48 \\
1987 & 9 & 68 & 4 & 0 & 0 & 81 \\
1988 & 20 & 91 & 6 & 0 & 0 & 117 \\
1989 & 39 & 63 & 4 & 0 & 0 & 106 \\
1990 & 38 & 70 & 4 & 0 & 0 & 112 \\
\hline
\end{tabular}




\begin{tabular}{lllllll}
\hline Year/Mag & $3.0-3.9$ & $4.0-4.9$ & $5.0-5.9$ & $6.0-6.9$ & $7.0-7.9$ & Total \\
\hline 1991 & 34 & 52 & 3 & 0 & 0 & 89 \\
1992 & 44 & 65 & 1 & 0 & 0 & 110 \\
1993 & 35 & 122 & 15 & 0 & 0 & 172 \\
1994 & 63 & 62 & 4 & 0 & 0 & 129 \\
1995 & 61 & 117 & 12 & 0 & 1 & 191 \\
1996 & 112 & 128 & 13 & 1 & 0 & 254 \\
1997 & 15 & 57 & 6 & 0 & 0 & 78 \\
1998 & 20 & 51 & 6 & 0 & 0 & 77 \\
1999 & 78 & 76 & 4 & 0 & 0 & 158 \\
2000 & 88 & 41 & 4 & 0 & 0 & 133 \\
2001 & 99 & 88 & 5 & 0 & 0 & 192 \\
2002 & 84 & 64 & 5 & 0 & 0 & 153 \\
2003 & 138 & 48 & 1 & 0 & 0 & 187 \\
2004 & 268 & 103 & 3 & 1 & 0 & 375 \\
2005 & 276 & 82 & 4 & 0 & 0 & 362 \\
2006 & 239 & 65 & 5 & 1 & 0 & 310 \\
2007 & 236 & 64 & 1 & 0 & 0 & 301 \\
2008 & 330 & 67 & 5 & 0 & 0 & 402 \\
2009 & 1 & 75 & 5 & 1 & 0 & 82 \\
Total & 2339 & 1752 & 123 & 4 & 1 & 4219 \\
\hline & & & & & & \\
\hline
\end{tabular}

Table 2. Magnitude and Log of cumulative frequency

\begin{tabular}{lllllll}
\hline Mag. & Freq. & fc & Perc. & $\mathrm{Nc}=\mathrm{fc} / 24$ & $\mathrm{Nc} * 100$ & $\log (\mathrm{Nc} * 100)$ \\
\hline 3.0 & 169 & 4219 & 4.005689 & 175.7917 & 17579.17 & 4.244998 \\
3.1 & 209 & 4050 & 4.953781 & 168.75 & 16875 & 4.227244 \\
3.2 & 232 & 3841 & 5.498933 & 160.0417 & 16004.17 & 4.204233 \\
3.3 & 285 & 3609 & 6.755155 & 150.375 & 15037.5 & 4.177176 \\
3.4 & 246 & 3324 & 5.830766 & 138.5 & 13850 & 4.14145 \\
3.5 & 281 & 3078 & 6.660346 & 128.25 & 12825 & 4.108057 \\
3.6 & 228 & 2697 & 5.404124 & 112.375 & 11237.5 & 4.05067 \\
3.7 & 229 & 2469 & 5.427826 & 102.875 & 10287.5 & 4.01231 \\
3.8 & 232 & 2240 & 5.498933 & 93.33333 & 9333.333 & 3.970037 \\
3.9 & 228 & 2008 & 5.404124 & 83.66667 & 8366.667 & 3.922552 \\
4.0 & 268 & 1780 & 6.352216 & 74.16667 & 7416.667 & 3.870209 \\
4.1 & 242 & 1512 & 5.735956 & 63 & 6300 & 3.799341 \\
4.2 & 250 & 1270 & 5.925575 & 52.91667 & 5291.667 & 3.723592 \\
4.3 & 206 & 1020 & 4.882674 & 42.5 & 4250 & 3.628389 \\
4.4 & 216 & 914 & 5.119697 & 38.08333 & 3808.333 & 3.580735 \\
4.5 & 183 & 598 & 4.337521 & 24.91667 & 2491.667 & 3.39649 \\
\hline
\end{tabular}




\begin{tabular}{|c|c|c|c|c|c|c|}
\hline Mag. & Freq. & $\mathrm{fc}$ & Perc. & $\mathrm{Nc}=\mathrm{fc} / 24$ & $\mathrm{Nc}^{*} 100$ & $\log \left(\mathrm{Nc}^{*} * 100\right)$ \\
\hline 4.6 & 138 & 415 & 3.270917 & 17.29167 & 1729.167 & 3.237837 \\
\hline 4.7 & 112 & 277 & 2.654658 & 11.54167 & 1154.167 & 3.062269 \\
\hline 4.8 & 84 & 165 & 1.990993 & 6.875 & 687.5 & 2.837273 \\
\hline 4.9 & 53 & 181 & 1.256222 & 7.541667 & 754.1667 & 2.877467 \\
\hline 5.0 & 39 & 128 & 0.92439 & 5.333333 & 533.3333 & 2.726999 \\
\hline 5.1 & 22 & 89 & 0.521451 & 3.708333 & 370.8333 & 2.569179 \\
\hline 5.2 & 15 & 67 & 0.355534 & 2.791667 & 279.1667 & 2.445864 \\
\hline 5.3 & 15 & 52 & 0.355534 & 2.166667 & 216.6667 & 2.335792 \\
\hline 5.4 & 12 & 37 & 0.284428 & 1.541667 & 154.1667 & 2.18799 \\
\hline 5.5 & 3 & 25 & 0.071107 & 1.041667 & 104.1667 & 2.017729 \\
\hline 5.6 & 8 & 22 & 0.189618 & 0.916667 & 91.66667 & 1.962211 \\
\hline 5.7 & 5 & 14 & 0.118511 & 0.583333 & 58.33333 & 1.765917 \\
\hline 5.8 & 2 & 9 & 0.047405 & 0.375 & 37.5 & 1.574031 \\
\hline 5.9 & 2 & 7 & 0.047405 & 0.291667 & 29.16667 & 1.464887 \\
\hline 6.0 & 0 & 5 & 0 & 0.208333 & 20.83333 & 1.318759 \\
\hline 6.1 & 2 & 5 & 0.047405 & 0.208333 & 20.83333 & 1.318759 \\
\hline 6.2 & 0 & 3 & 0 & 0.125 & 12.5 & 1.09691 \\
\hline 6.3 & 0 & 3 & 0 & 0.125 & 12.5 & 1.09691 \\
\hline 6.4 & 1 & 3 & 0.023702 & 0.125 & 12.5 & 1.09691 \\
\hline 6.5 & 0 & 2 & 0 & 0.083333 & 8.333333 & 0.920819 \\
\hline 6.6 & 0 & 2 & 0 & 0.083333 & 8.333333 & 0.920819 \\
\hline 6.7 & 0 & 2 & 0 & 0.083333 & 8.333333 & 0.920819 \\
\hline 6.8 & 1 & 2 & 0.023702 & 0.083333 & 8.333333 & 0.920819 \\
\hline 6.9 & 0 & 1 & 0 & 0.041667 & 4.166667 & 0.619789 \\
\hline 7.0 & 0 & 1 & 0 & 0.041667 & 4.166667 & 0.619789 \\
\hline 7.1 & 0 & 1 & 0 & 0.041667 & 4.166667 & 0.619789 \\
\hline 7.2 & 1 & 1 & 0.023702 & 0.041667 & 4.166667 & 0.619789 \\
\hline
\end{tabular}

\subsection{Classification of Events According to Their Frequencies}

In order to investigate the variation of the seismicity in the study area, the earthquakes were classified according to their frequency as shown in Table 3.

Table 3. Classification of events according to their frequencies at interval of 8-year

\begin{tabular}{lllllll}
\hline Year/Mag & $3.0-3.9$ & $4.0-4.9$ & $5.0-5.9$ & $6.0-6.9$ & $7.0-7.9$ & Total \\
\hline $1986-1993$ & 231 & 564 & 40 & 0 & 0 & 835 \\
$1994-2001$ & 536 & 620 & 54 & 1 & 1 & 1212 \\
$2002-2009$ & 1572 & 568 & 29 & 3 & 0 & 2172 \\
\hline
\end{tabular}


The time interval of 8 years i.e. (1986-1993), (1994-2001) and (2002-2009) was used. The frequency distribution of earthquakes that occurred within the time interval of 8 years in 1994-2001 was higher than the previous 8 years interval and lesser than the following 8 years interval. This shows that the relative motion between the intraplates and mining activity are increasing with time and lead to large accumulation of tectonic stress. The accumulation of stress was in turn responsible to more events with time. Increase in magnitude 6.0-6.9 from 1 during second 8 years to 3 during last 8 years suggests that a devastative earthquake is on increase in the study area. This is shown in Table 3 and Figure 2.

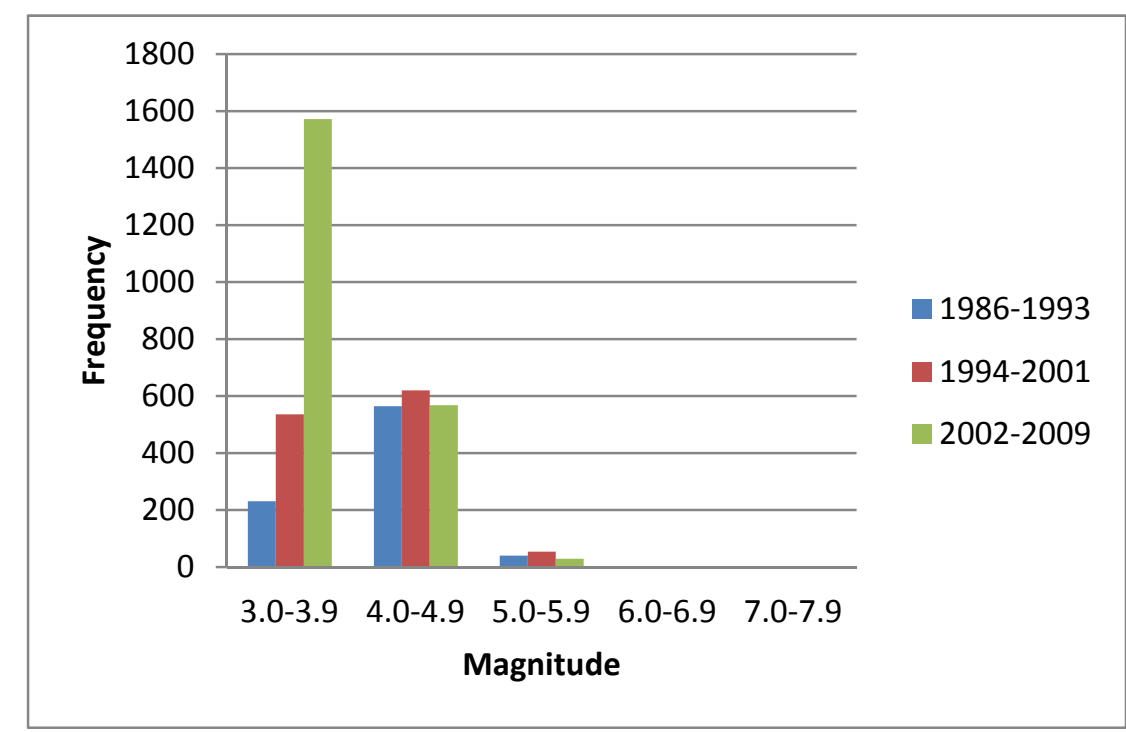

Figure 2. Comparison of frequency- Magnitude distribution over 8-year interval

\subsection{Measurement of Central Tendencies and Spread}

After presenting the data in Table 1, the central tendency was performed to obtain rough estimate of the average magnitude, relative frequencies as well as spread. For these purposes mean, mode, median and standard deviation were computed for magnitude and depth values as shown in Table 4.

Table 4. Central tendencies and spread

\begin{tabular}{lll}
\hline & Depth & Magnitude \\
\hline Mean & 24.49 & 3.88 \\
Mode & 33.00 & 3.50 \\
Median & 24.00 & 3.80 \\
Standard Deviation & ---- & 0.16 \\
\hline
\end{tabular}

\subsection{Pictorial Construction}

The histogram of the data was constructed. Figure 3 shows the histogram of frequency versus magnitude for 4219 events (1986-2009). 


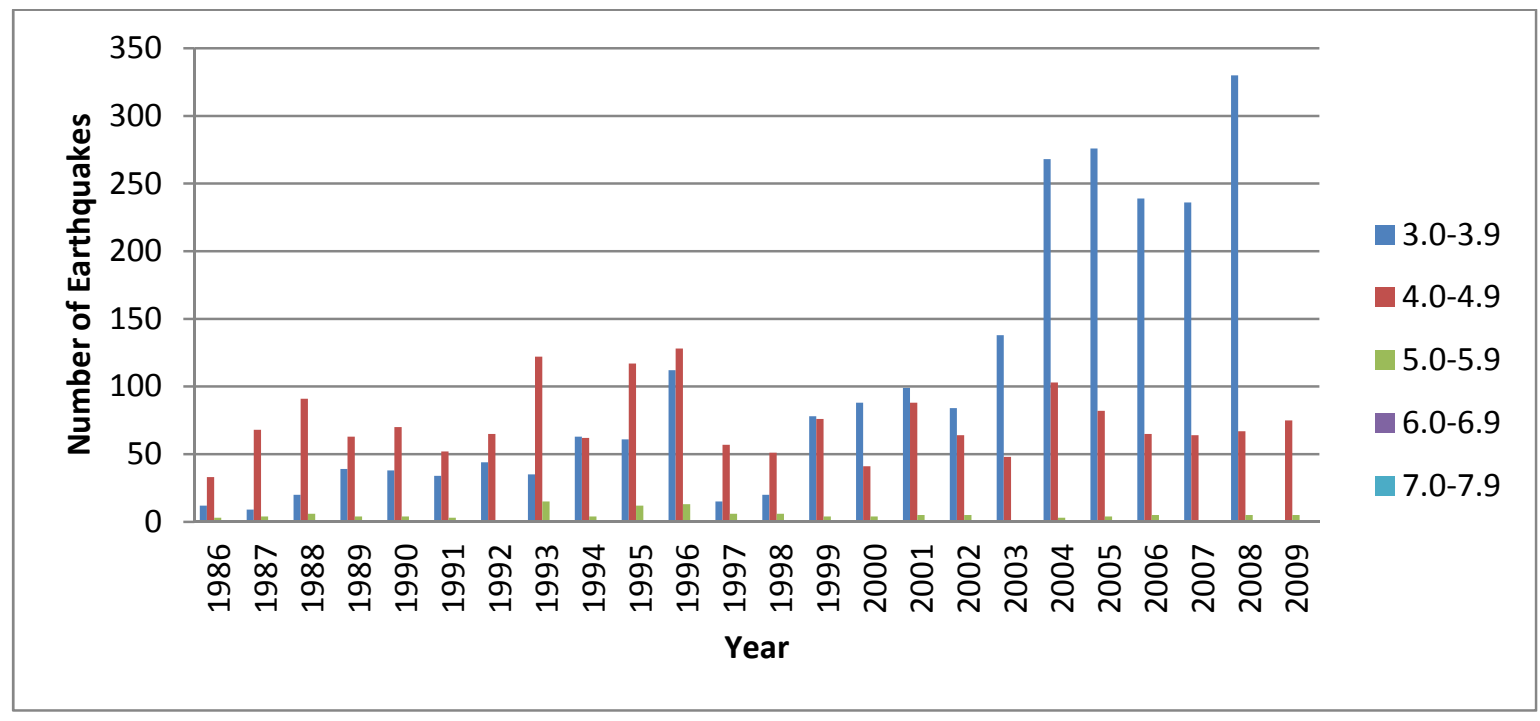

Figure 3. Histogram of the earthquakes $(\mathrm{M} \geq 3.0)$ in South Africa (1986-2009)

The histogram revealed that events of magnitude between 3.0 and 3.9 were most frequent, follow by magnitude 4.0-4.9 and the least frequent magnitude was 7.0-7.9 which was only one. This suggests that South Africa is predominantly dominated by small earthquakes.

\subsection{Gutenberg-Richter Relation}

Many different ways are explored to study earthquakes. Earthquake frequency-magnitude relation is one of the ways to examine seismic activity in an area (Darwin, 1845), Schwartz and Coppersmith (1984) and Ghosh, (2007), the exponential model that implies that earthquakes on a given fault follow the Gutenberg-Richter relationship (G-R). The $\mathbf{a}$ - and $\mathbf{b}$-value in the G-R power law are parameters that supply essential information in seismotectonic studies and seismic risk analysis; hence their correct computation reveals important information on seismology of an area.

The Gutenberg-Richter frequency-magnitude linear relationship is given as in Equation (2) and graph of Log $\left(\mathrm{Nc}^{*} 100\right)$ against earthquake magnitude (Figure 4) gives $\mathbf{a}$ as the intercept on $\mathrm{Log}\left(\mathrm{Nc}^{*} 100\right)$ axis and $\mathbf{b}$ as slope of line of best fit.

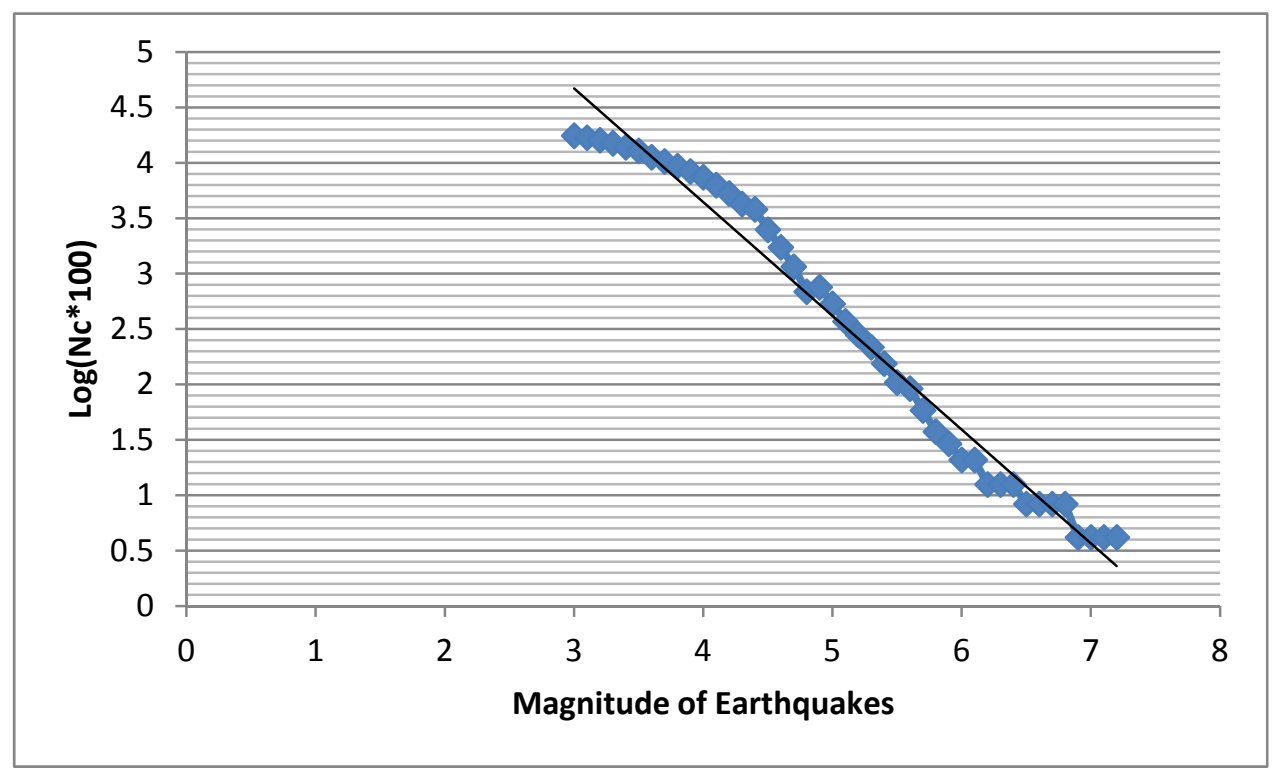

Figure 4. $\log \left(\mathrm{Nc}^{*} 100\right)$ against magnitude with line of best fit 
From Figure 3, the slope, which is b is equal to1.23 and Intercept, which is a* is equal to 7.75.

Therefore since intercept, $\mathrm{a}^{*}=\mathbf{a}+2$, then $\mathbf{a}=7.75-2=5.75 ; \mathrm{b}=1.23$ and $\mathrm{a}=5.75$.

\subsection{Time Series Analysis}

Another way of representing the data is to consider the trend. This was done by using the line graphs illustrating the frequency distributions of different magnitude ranges. The time series analysis (moving average) was also plotted and contrasted with line graph. The 3-year moving average was employed to decompose the time series into either cyclic trend, seasonal and or random variations. The result is presented in Figure 5.

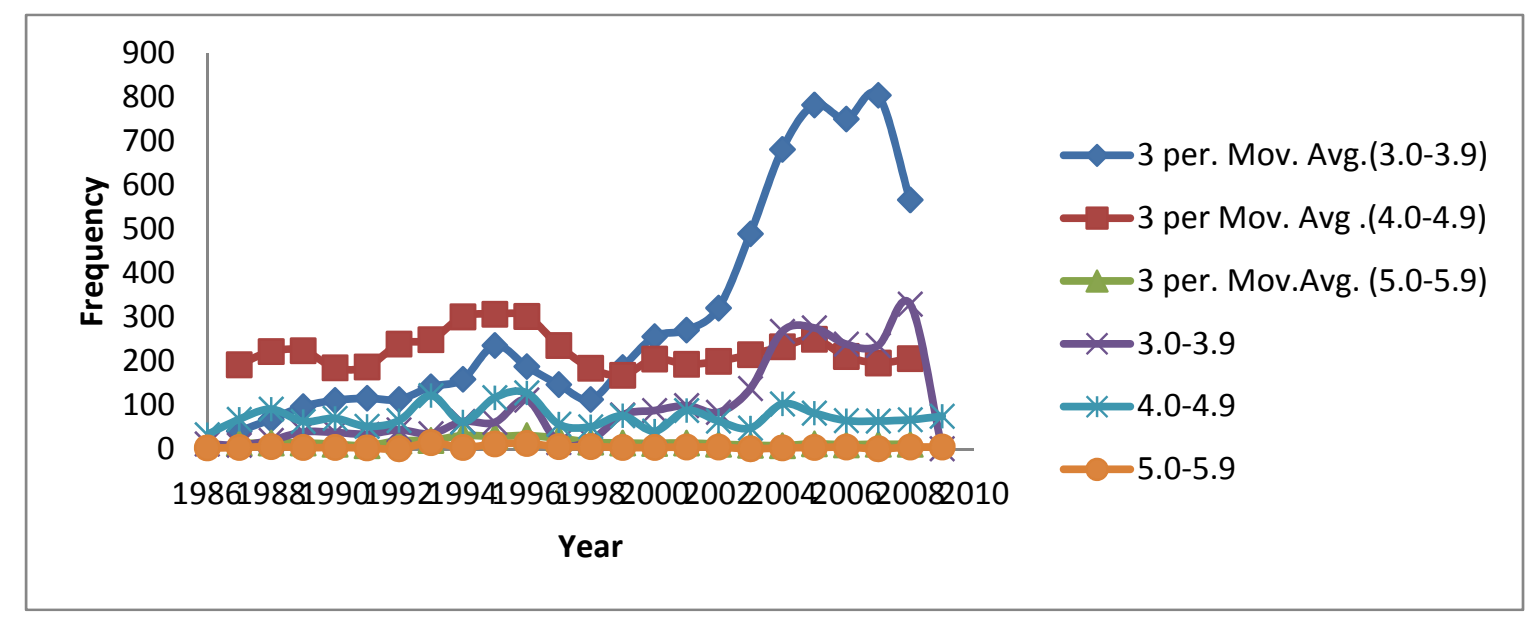

Figure 5. Line graph and moving average of earthquake $(M \geq 3)$ in South Africa (1986-2009)

\section{Results and Discussions}

Figure 6 shows seismicity distributions of Southern Africa region within studied period, the distribution is cluster in southern part of South Africa. There were few events in Mozambique, Zimbabwe and Madagascar.

The histogram of the data constructed in Figure 2 shows that the mode is between magnitude 3.0 and 3.9. This is in agreement with computed measure of central tendency that gave the mode as 3.5 for the whole data set. Moreover, the mean magnitude of overall for the whole distribution is 3.88 while the median is 3.8

These show that most of the seismic events in Southern Africa are in the category of small types.

The history of tectonic activities and the central tendency analysis confirm that Southern Africa is a region of minor earthquakes. Moreover, this region is located in the intraplate belt, where large earthquakes are rare. Intraplate earthquakes constitute just about $1 \%$ of seismic events on the global level. Earth tremors from mining activities also constitute these earthquake figures. All these are conspicuously shown in Figure 1 and Table 1. The percentage compositions of the overall data are $55.4 \%, 41.5 \%, 2.9 \%$ and $0.1 \%$ for the $3.0-3.9,4.0-4.9$, 5.0-5.9 and 6.0-6.9 magnitude ranges respectively. The standard deviation value of 0.16 relative to the computed mean value indicates that the data does not have a significant spread. This implies that seismic events in this area (Southern Africa) are not experiencing any significant spread which is corroborated by the tremors occurring at shallow epicenters and other minor low depth events.

The Gutenberg-Richer relation, for the region gives a low value of a 5.75 from figures 3 indicating that earthquake occurrence in this region is relatively low. The value of a indicates that the earthquake activity in the region is low, a region of low seismicity.

The Figure 3 is more reliable because of the cumulative frequency distribution. The value of $\mathbf{b}$ here is 1.23 (greater than 1).

The value of $\mathbf{b}$ here is considered large, which is characteristic of regions with small earthquakes. This shows that Southern Africa is characterized with minor earthquakes, a property of intraplate regions. The East African Rift system which extends to most seismically active portion of Southern Africa (Mozambique, Zimbabwe and Northern Botswana) is also included. 


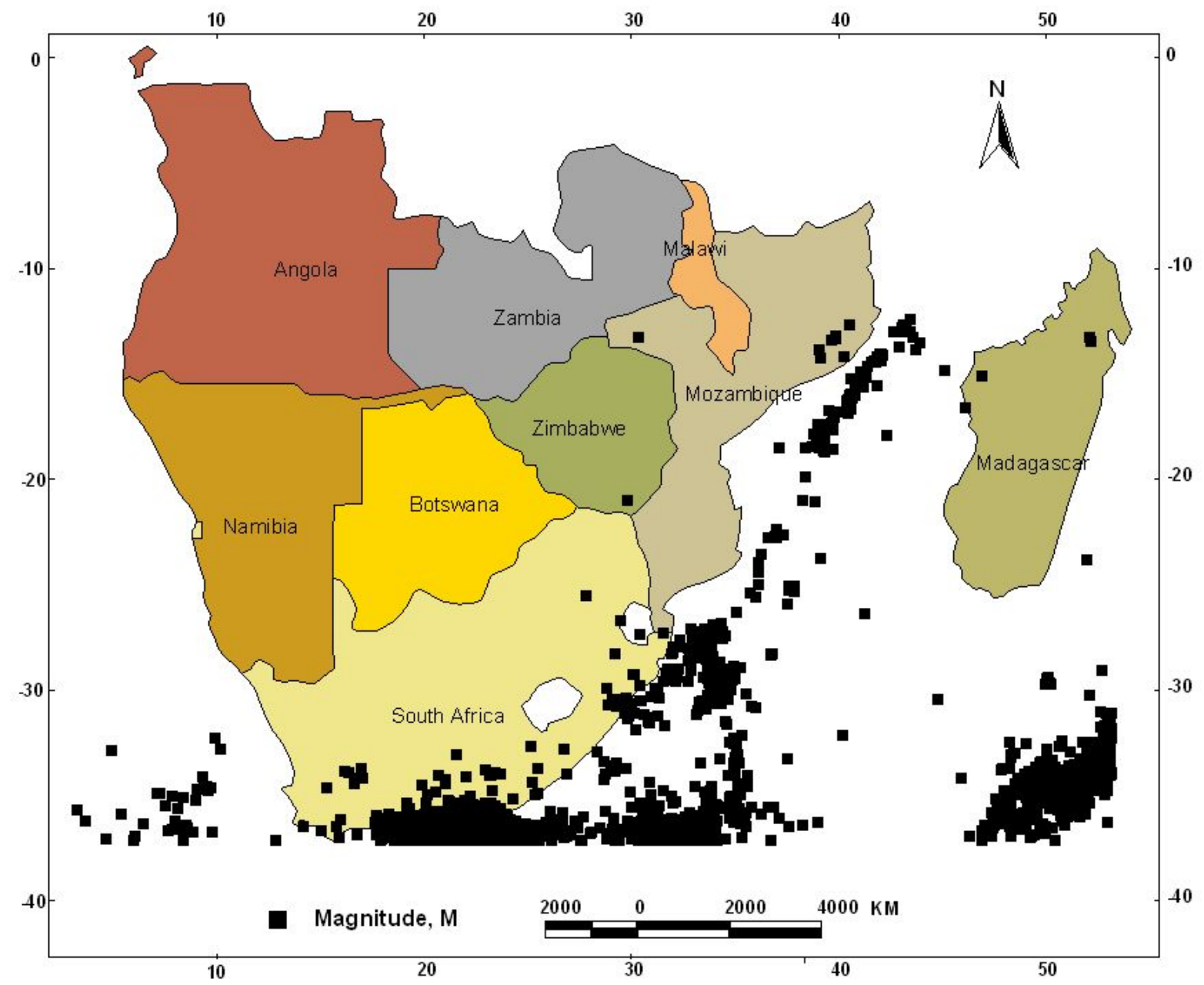

Figure 6. Map of the study area showing seismicity distributions $(\mathrm{M} \geq 3)$ between1986-2009

From laboratory experiments, low stress implies high value for $\mathbf{b}$, therefore the shallow depths predominant in the whole region which result in low tectonic stress.

These ideas are however not exhaustive because the region is of a poorly understood tectonic deformation and the value of $\mathbf{b}$ so far have not been really understood from research.

The line graphs give the observed magnitude ranges for the period under consideration. These are pictures of the frequency distribution of earthquakes for the different ranges of magnitude. The three-year-moving average for Southern Africa behaves approximately like the line graphs when contrasted (Figure 4).

The rate of seismic activity is irregular for the 3.0-3.9 and the 5.0-5.9 magnitude range and somewhat irregular or fluctuating for the 4.0-4.9 range.

Consequently, an inference can be made that these trends are likely to continue in the nearest future, in which case, there would be no serious earthquake in Southern Africa region.

Nevertheless, there is a need for caution because of the poorly understood tectonic activities of intraplate deformation and the great uncertainties in earthquake occurrence.

South Africa is a deep-level mining area which involves working in the earth's crust where there is naturally occurring seismicity, which occurs as the continental plates shift and in reaction to changes in the force fields in the earth's crust. So if the activities of the mining were not managed or controlled, it may aggravate the occurrence of earthquakes. 


\section{Conclusion}

Southern Africa can be generally regarded as a region of low seismic activity. Even though, it is believed that this region is an extension of the East African rift, the portion that constitutes this extension is still of light or at most moderate seismicity.

Intraplate seismic zones globally have been known to experience rare earthquakes occurrences. Southern Africa belongs to this zone it can be concluded from the study of seismicity occurrence in 24 years that the study area rarely experience earthquakes.

Consequently, it should not be expected that any serious earthquake would occur in Southern Africa in the not too distance future. That implies that the probability that a large earthquake would occur in the region is low. However, that does not mean that it cannot occur because the phenomenon of earthquake forecast or prediction is still a complicated issue.

Despite this conclusion on earthquake occurrence in Southern Africa and the unpredictability of seismic activities in intraplate seismic regions, there is need for some caution. The Structural Engineers and builders should adhere strictly to the earthquake resistant code before putting all categories of structure in place.

Reasonable provisions should be made for the design and detailing of low buildings in structures close to the mining areas to check damages due to tremors and light earthquakes. High rise buildings needed to be designed and constructed to resist earthquakes considered as moderate.

\section{References}

Abercrombie, R. E. (1995). Earthquake source scaling relationships from-1 to 5 ML using seismograms recorded at 2.5-km depth. J. Geophys. Res., 100, 24015-24036.

Amiri, G. G., Razeghi, H. R., RazavianAmrei, S. A., Aalaee, H., \& Rasouli, S. M. (2008). Seismic Hazard Assessment of Shiraz, Iran. Journal of Applied Sciences, 8, 38-48. http://scialert.net/abstract/?doi=jas.2008.38.48

Darwin, C. (1845). The Voyage of the Beagle (1975 Reissue). London: J. M. Dent.

Ghosh, A. (2007). Earthquake frequency-magnitude distribution and interface locking at the middle America Subduction Zone near Nicoya Peninsula, Costa Rica. Georgia Institute of Technology. http://smartech.gatech.edu/handle/1853/16288

Gutenberg, B., \& Richter, C. F. (1944). Frequency of earthquakes in California. Bull. Seismol. Soc. Am., 34, 185-188.

Linzer, L. M., Bejaichund, M., Cichowicz, A., Durrheim, R. J., Goldbach, O. D., Kataka, M. O., ... Webb, S. J. (2007). Recent research in seismology in South Africa. Afr. j. sci., 103, 9-10.

Schwartz, D. P., \& Coppersmith, K. J. (1984). Fault behavior and characteristic earthquakes: Examples from the Wasatch and San Andreas Fault Zones. J. Geophys. Res., 89, 5681-5698.

Uzoegbo, H. C., \& Warnitchai, P. (2000). On the need for a regional policy on seismic resistant design and construction. Rotterdam, Netherlands. Retrieved from http://www.irb.fraunhofer.de/CIBlibrary/search-quick-result-list.jsp?A\&idSuche=CIB+DC8968

Uzoegbo, H. C., \& Li, K. (2002). Mine-induced seismic events and its effect on nearby settlements in South Africa. National Research Foundation (NRF) and Hydraform Africa Ltd. Retrieved from http://www.iitk.ac.in/nicee/wcee/article/14_S03-028.PDF 